\title{
Measurement of Myocardial Contractility in the Ischemic Heart - A Disease Immanent Uncertainty
}

\author{
Jens Broscheit \\ Department of Anethesiology, University Clinics of Würzburg
}

Germany

\section{Introduction}

The present compilation of scientific publications deals with the evaluation of a parameter of myocardial contractility ( $\mathrm{E}^{\prime}$ es); the parameter can be exclusively measured using ultrasound, i.e. noninvasive and can be used for a load-independent quantification of myocardial contractility.

The standard procedure for measuring left ventricular (LV) contractility is by use of a conductance catheter with which LV volume and LV pressure can be determined simultaneously. In 1973, Sagawa (1) was the first to use this catheter, which had been developed at the University Hospital Leiden, and he was able to show that an elastance curve can be determined from a series of loop diagrams which were obtained under acute preload reduction. The slope of the elastance curve $\left(\mathrm{E}_{\mathrm{es}}\right)$ increased when the positive inotropic substance isoprenaline was administered (Fig. 1).

For clinical use, however, the catheter is a monitoring procedure which is too invasive and thus involves too many risks; in the past few years there have been considerations to replace this procedure with one that is less invasive.

In 1994, Gorscan (2) presented a study with which he was able to show that LV volume can be estimated by continuous echocardiographic determination of the cross-sectional LV area and in 1997 Deanault from the same working group (3) showed that LV pressure can be approximated with the pressure from the radial artery. They generated a loop diagram from these surrogate parameters with which they could estimate LV contractility. In the years 2001-2003 the mathematicians Danielsen, Ottesen and Paladino (4-6) from the University of Roskilde published a model equation from which we deduce that, with simplified assumptions, the Doppler sonographic arterial flow would have to change in proportion to pressure and we asked ourselves if contractility could also be estimated with a flow-area relationship.

\section{Question}

The thoughts presented here are a model for measuring LV contractility as it could be determined in the patient, i.e. exclusively based on ultrasound and thus not very invasive. 


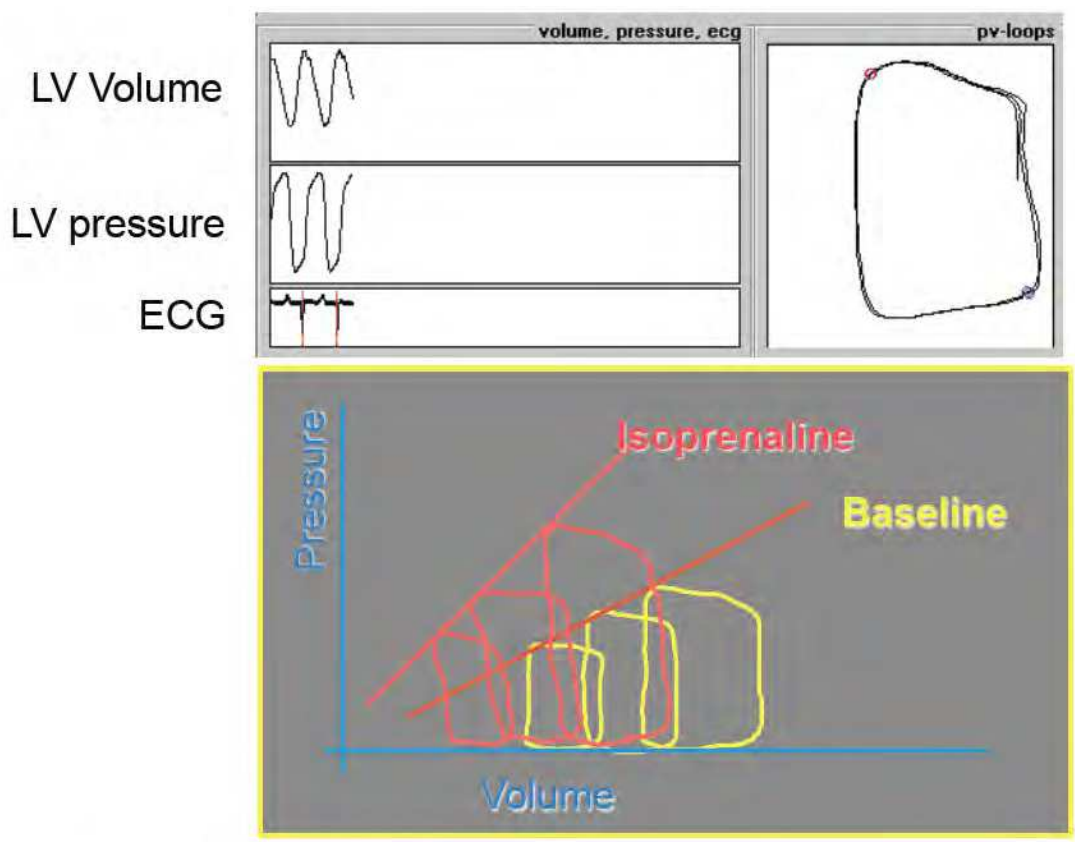

Sagawa K, et al. Am J Cardiol 1977; 40:748-753

Fig. 1. Determination of the properties of elastance curves

This raises the question of whether contractility can in fact be estimated using the index $\mathrm{E}_{\mathrm{es}}^{\prime}$ which has been deduced from this theoretical model.

If the elastance of the flow-area relationship is exclusively considered as a surrogate parameter to estimate myocardial contractility in the classical sense, then $E^{\prime}$ es is not a new parameter. If it is assumed, however, that the elastance of the flow-area relationship is based on a completely new mathematical model, i.e. that of the mathematicians Danielsen, Ottesen and Paladino, then we are possibly dealing with a new parameter and deviations between the classical parameter $\mathrm{E}_{\mathrm{es}}$ and $\mathrm{E}_{\mathrm{es}}^{\prime}$ are then starting points for new examinations.

\section{Background}

\section{Ultrasound-based determination of myocardial contractility: theoretical principles}

The ability to actively shorten the cardiac muscle, i.e. of contractility, of the left ventricle is based on a complex process $(7,8)$ during which individual mechanisms have to follow one another precisely. Muscle contraction is based on mechanisms and interactions associated with muscle proteins, enzymes, ions and energy sources. The large-scale structure, as well as the small-scale structure of the muscle, are involved in the contractility of the hollow muscular organ which forms the left chamber of the heart or left ventricle. Apart from power transmission towards contraction, the prevention or diversion of shearing forces is an important task which the muscle carries out through mechanisms of mechanical connections, but also through mechanisms of regulation by synchronizing the contraction of the muscle fibers. 
First attempts to describe the contractility of a hollow muscular organ from a mechanical point of view date back to Otto Frank in 1985 (9). Frank determined the pressure of the individual end-diastolic volumes by conducting experiments with a single chamber frog heart as well as the maximum pressure recruitable from this relaxation period (isovolumeric maximum) and the maximum ejection fraction (isotonic or isobaric maximum). The curves established from this resulted in a pressure-volume diagram in which the maximums to be achieved from the relaxation period were connected through the contraction curve (2). Otto Frank deduced the cardiac cycle from this:

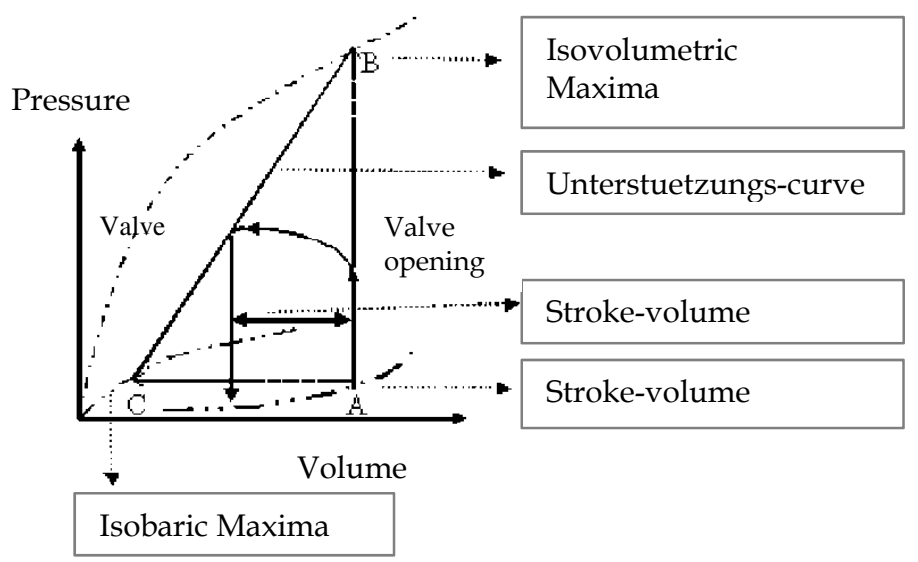

Fig. 2. LV pressure-volume diagram by Otto Frank.

The ventricle is filled with volume (preload) and during the process internal pressure in the chamber increases. Then the pressure in the chamber increases through contraction along the isometric maximum against the closed valve until the valve opens which, during the relaxation phase (diastole), prevents reflux from the aorta into the ventricle. While the heart is pumping out volume against the arterial load (afterload), it is pumping in the sense of an auxotonic contraction; this leads to a further increase of arterial pressure and to a decrease in volume through ejection in the ventricle. During the following relaxation phase the pressure in the ventricle decreases to reach its resting level and the chamber is filled again. The cardiac cycle can thus be described through a pressure-volume relationship which is known as the "work diagram" in literature.

In later experiments, Starling (10) deduced the s-shaped connection between the surface of the work diagram and the necessary preload. The two main differences between the concept described by Otto Frank and the one developed by Starling are that the contraction of the left ventricle cannot only be described as a function of filling or preload, but also as a function of time. Another difference is that when it comes to measurements, the left ventricular function is always determined in connection with the arterial vascular system behind it.

In 1959, Warner deduced the calculation of ventricular compliance $C$ from the correlation described by Frank by relating volume $V_{v}$ and the corresponding pressure $P_{v}$ at the end of diastole and at the end of systole 


$$
C=\frac{V_{v}}{P_{v}}
$$

and thus created a constant. From this formal approach, two different mathematical terms for the description of LV contraction can be concluded. In 1961, Seelen (11) described contraction through fixed capacitive reactance in series with pressure varying depending on time and in 1973, Suga (1) defined ventricular elastance $E(t)$ through an inverse function of the compliance $C(t)$ function.

$$
E(t)=\frac{P_{v}(t)}{V_{v}(t)-V_{d}}
$$

with the SI-unit $\left[\mathrm{m}^{-4} \bullet \mathrm{kg} \bullet \mathrm{s}^{-2}\right]$, while $V_{d}$ represents constant, diastolic volume. The index (t) in this case means that the end-systolic point was determined using an iterative method in which the same loop is crossed by a tangent several times and with varying time (timevarying elastance). In the experimental determination of $E(t)$, the same problems arise as in the correlation already developed by Starling. The index $E(t)$ cannot be determined separately from the vascular system and it is not a function of time.

To get around these problems, Beneken 1965 (12) developed a closed-loop model of the cardiovascular system, which was based on the work of Liljestrand 1938 (13) and Hill 1922 (14), and in which contraction of the heart is calculated through the contractile element described by Hill, embedded in a three-element windkessel model. Further geometrical adjustments yielded an n-element model, which was mathematically described with the finite-element method.

Based on the evaluation described by Hill, Danielsen (4) later developed a model which differentiated between an isovolumetric ventricle and an ejecting left ventricle under arterial load. In the latter model, the direct proportional correlation between arterial pressure $P_{a}$ and $L V$ outflow $Q_{v}$ was deduced as follows:

$$
\dot{P}_{s}=-\frac{1}{R_{s} C_{s}} P_{s}+\frac{1}{C_{s}} Q_{v}
$$

with $R_{s}$ as a global peripheral resistance, $R_{0}$ as characteristic aortic impedance, $\mathrm{C}_{\mathrm{s}}$ as total arterial compliance, $P_{s}$ as systolic pressure and $P_{s}$ as the change of arterial pressure with time. This equation can be transformed to This equation can be transformed to:

$$
\dot{Q}_{v}=-\frac{1}{L_{v}} P_{s}-\frac{R_{o}}{L_{v}} Q_{v}+\frac{1}{L_{v}} P_{v}(t, V),
$$

with $L_{v}$ as inductance directly above the aortic valve and $Q_{v}$ as a change of flow with time. With the simplified assumption that $L_{v}$ is constant, the above equation can be simplified as follows.

$$
P_{a}=P_{s}+R_{o} Q_{v}
$$

With the assumption that $R_{0}$ is constant and $P_{a}$ changes in direct proportion to $P_{s}$ the equation is: 


$$
P_{a} \approx Q_{v}
$$

Olufsen (15) showed in his one-dimensional dynamic model of the systemic arteries that, corresponding to the Navier-Stokes equation, pressure changes directly proportional to flow in large vessels such as the arteria carotis communis. The model-based experimental examinations confirm that the flow generated through the left ventricle is the connecting link between the heart and vessel blood system.

Against this backdrop, our work group had the idea of developing an index $E^{\prime}{ }_{\text {es, }}$, analogous to $E(t)$, based on the iteratively determined end-systolic points on the work diagram. This index $E^{\prime}{ }_{e s}$ was to be determined by $V_{d}(t)$ and blood flow $V_{v}(t)$ of an artery in proximity to the heart:

$$
E_{e s}^{\prime}=\frac{V_{v}(t)}{V_{v}(t)-V_{d}}
$$

with the SI unit [s-1]. The ventricular volume, measured during several cardiac cycles, can be determined using ultrasound technology by estimating it with the help of the surface A in the transgastral short-axis-view. Blood flow $Q$ can be estimated through the blood flow velocity $\mathrm{F}$ in the arteria carotis communis measured with the Doppler technology. This then yields the following equation:

$$
E_{e s}^{\prime}=\frac{F_{v}(t)}{A_{v}(t)-A_{d}}
$$

The deduced index $E^{\prime}{ }_{e s}$ displays the following important differences compared to the index $E_{e s}$ :

1. By implementing blood flow velocity, the index becomes a function of time.

2. By measuring blood flow velocity in a large artery, the index becomes connected to the vascular system.

3. Through the measuring method used, the index $E^{\prime}{ }_{e s}$ can be completely determined in a noninvasive way, as both $F$ and $A$ are ultrasound parameters.

\section{Measuring methods used}

The measuring methods used in this context are conductance and ultrasound methods. Using these methods, myocardial contractility was measured.

\section{Conductance catheter method}

A conductance catheter was used for the simultaneous recording of LV pressure and the volume signal (16). The catheter consists of pressure-conductivity transducers. While the blood pressure signal was mechanically measured at the tip of the catheter using a pressure transducer and was subsequently transformed into electric impulses, determination of volume is carried out electromagnetically by measuring the conductivity of the surrounding compartments. The catheter consists of four electrodes and one pressure sensor. The electrodes are fitted below the pressure sensor in pairs. The measurement of cardiac blood volumes using these electrodes is based on an electric field which is established through the outer electrodes in the left ventricle. Two potential differences at the inner electrodes are continuously recorded to measure the conductance between the electrodes in the ventricle. 
With the formula

$$
V_{i}(t)=\frac{1}{\alpha} \bullet \rho L_{a^{2}}\left(G_{i}(t)-G_{p i}\right)
$$

intraventricular volume $\mathrm{V}(\mathrm{t})$ is calculated. With a being a volume calibration factor, $p$ being the electric resistance of blood, $L$ being the distance between the electrodes, $G_{i}$ describing the overall conductance and $G_{p i}$ describing the conductance of the surrounding tissue; this conductance is called "parallel conductance". This calculation makes a continuous and in vivo recording of volumes in real-time possible.

\section{Ultrasound method}

Using the ultrasound-Doppler method, the flow velocity of erythrocytes can be measured with the help of the Doppler effect. The Doppler effect arises because echoes reflected by the erythrocytes have higher or lower frequencies than the signals sent out, depending on the flow velocity and flow direction. The differences in frequency are implemented electronically in readable and recordable curves. In the continuous-wave Doppler (CW Doppler) technique, which is used for detection, one transmitter and one receiver work simultaneously and continuously in the transducer. By mixing it with suitable high frequency signals and with electronic filters, the spectrum of the Doppler frequencies or velocities and the direction can be determined from the returning wave in the evaluation electronics. The disadvantage of this method is that it is not possible to determine the base range of the Doppler echo; however, even relatively high velocities can be recorded.

With the two-dimensional, light-modulated presentation of the echoes, an immediately visible, animated picture is generated through energy and intensity proportional light points that vary according to brightness and as a result of a scan carried out in two directions and in layers. Tissue structures become visible because the points that are represented in shades of gray in relation to the intensity of the echo - as far as they originate from comparable structures - flow together to form areas and lines. The semi-automatic detection of contours serves to detect endocardial interfaces within the "region of interest" (ROI). Semi-automatic contour tracking is based on a seeded ROI algorithm which combines all adjacent pixels within a user-defined signal intensity area. The selected (seed) pixel is the starting point. In automatic segmentation, a small ROI can be positioned in the area of interest. The signal intensity area important for the growth algorithm is automatically taken from the ROI statistics (minimum to maximum value). The area defined in this way can be corrected interactively. For an ROI correction, the boundaries are activated by a click of the mouse. These boundaries can also be corrected interactively. After having selected the acoustic windows relevant for the approximation of volume - transgastral short-axis-view of the left ventricle - the window setting at an enddiastolic phase image was adjusted to achieve an ideal contrast for the detection of endocardial boundaries. This window setting as well as the curves of the ventricular area presented in the ultrasound image were then checked in all phase images of the cardiac cycle. This setting was used for the following examinations.

\section{Measuring parameters}

End-systolic elastance is derived from the end-systolic pressure-volume relation (ESPVR). The elastance model was introduced by Sagawa and Suga. (17). Using isolated rabbit hearts, 
they made the observation that the end-systolic pressure volume coordinates move along a straight line in the case of acute preload reduction. This could also be observed when acute preload reduction occurred at different levels of dilatation of the left ventricle (Fig. 1) is it a picture legend? A difference is made between two elastances: time-dependent elastance $\mathrm{E}_{\max }$ and time-varying elastance $\mathrm{E}_{\mathrm{es}}$.

In this model, $\mathrm{E}_{\max }$ describes the slope of the end-systolic linear regression curves.

In this context the time-dependent elastance $E(t)$ from the equation

$$
E(t)=\frac{P(t)}{V(t)-V L(t)}
$$

is determined, with $\mathrm{P}(\mathrm{t})=$ instantaneous intraventricular pressure; $\mathrm{V}(\mathrm{t})=$ instantaneous intraventricular volume; $\mathrm{V} 0=$ volume, if $\mathrm{P}(\mathrm{t})=0$. E es is elastance at the point in time when $\mathrm{E}(\mathrm{t})$ reaches its maximum, i.e. when active contraction is at its maximum. $\mathrm{E}_{\mathrm{es}}$ is calculated from the slope of the linear regression curves, which is time-varying and results from the maximum of the points.

$$
\frac{P}{V-V_{0}}
$$

The calculation of maximum is repeated several times through fixed point iteration until the slope of the line is constant. $E_{e s}$ is determined if, in case of fluctuations in afterload, the time in which the end-systolic state is reached fluctuates and consequently ESPVR does not exactly meet the angle of the loop diagram and $E_{\max }$ is calculated from points which lie ahead of the end-systolic one. $\mathrm{E}_{\max }$ is then steeper than $\mathrm{E}_{\mathrm{es}}$. While $\mathrm{E}_{\max }$ is the basis for models concerning the mathematical adjustment of the left ventricular function, $\mathrm{E}_{\mathrm{es}}$ is used for the experimental quantification of LV contractility. The calculation formula for the indices $E_{\max }$ and $E_{e s}$ is not presented in a consistent manner in literature, however. The index $\mathrm{E}_{\text {es }}^{\prime}$ was determined analogous to the index Ees, with the difference that the flow-volume diagram was the basis for calculation

A positive inotropic effect, induced through dobutamine, can be observed through an increase of $\mathrm{E}_{\mathrm{es}}$, i.e. an increase in the slope of the linear regression curves. The opposite occurs in decreasing inotropy, when it is triggered by a $\beta$-receptor blocker like esmolol (Fig. 1 ) is it a picture legend?, for instance.

\section{Hemodynamic interventions}

The main goal of the studies were the controlled, targeted and pathophysiological interventions with sequential application of dobutamine, esmolol, akrinor, hydroxyethyl starch and sodium nitroprusside, with which the degree of correspondence of the two measuring methods was determined. The properties of these substances, which will be described in the following section, were the reason for them being used.

\section{Modification of contractility through dobutamine and esmolol}

Dobutamine has the effect of an a1-, $\beta 1$ - and $\beta 2$-agonist, while $\beta 1$ stimulation of the heart is the most immediate effect. The main effects of dobutamine result from this, i.e. the increase of contractility of the myocardial cells and a dosage-dependent marked increase in heart 
rate. This leads to increased stroke volume (SV) and cardiac output (CO). The substance has a short half-life period of approx. 2 minutes and is broken down in inactive metabolites. It is thus applied per continuitatem. needs spell check here - it is the latin spelling and ok!.

Esmolol has the effect of a $\beta 1$-antagonist and is thus cardioselective at the myocardium. The main effects are a decrease in heart rate and the inhibition of contractility. This leads to a decrease in stroke volume and in cardiac output. The half-life period is only approx. 9 minutes, as esmolol, in contrast to other beta blockers, is not broken down in an organdependent way, but is metabolized by esterases hydrolases. For this reason, esmolol has to be administered in a continuous or repetitive way.

\section{Modification of load through hydroxyethyl starch, akrinor and sodium nitroprusside}

In statistics or kinematics, load is a unit of measurement for the force that works on a medium. Accordingly and as far as the left ventricle is concerned, preload is the force that results in the extension of fibers at the end of diastole or directly before systole and which is limited by the maximum resting length of the muscle fiber. Afterload is a force influencing the ventricle; this force counteracts ejection out of the ventricle into the cardiovascular system. In practice, preload is referred to as the end-diastolic volume in the heart. The fact that the standard index $\mathrm{E}_{\mathrm{es}}$ is load-independent, i.e. that changes in preload and afterload of the left ventricle mostly do not change the contractility index over wide periods, is an important characteristic of this measurement. Changes in load induce changes in contraction force, contractility remains unchanged, however.

Hydroxyethyl starch is a synthetically produced polymer and, like dextrane, and gelatine is used for the substitution of intravascular volume. End-diastolic volume was thus increased.

Akrinor is a fixed combination of the two active ingredients cafedrin and theodrenaline. Blood pressure is primarily increased through an alpha-receptor-mediated, arterial vasoconstriction. Then contractility and heart rate are slightly increased through a less intense stimulation of beta receptors.

Apart from inhibiting guanylate cyclase and consecutively releasing nitric oxide in the smooth musculature of the vascular wall, sodium nitroprusside has a vasodilative effect on both at the resistance vessels of the arterial system and at the capacitance vessels of the venous system. Due to the short half-life period of less than 10 minutes, continuous administration is necessary.

\section{Determination of preload recruitable stroke work and elastance by the relation of arterial blood flow velocity to left ventricular area}

The question whether contractility can be estimated with a flow-area relationship was the starting point for this study.

In a first animal experiment, 8 Göttinger minipigs were studied in an open chest preparation. An arterial manometer was placed in the femoral artery and a microtip catheter for the measurement of LV pressure was advanced into the left ventricle from the apex. A flexible TEE probe was fixed on the myocardium to sonographically estimate volume with LV area measurement. Finally, the arteria carotis communis was dissected to fix a U-shaped 8-MHz CW Doppler probe on it. Then an inferior vena cava occlusion was performed to 
reduce preload. A central venous catheter was implanted for the pharmacological intervention. Via this catheter, contractility was sequentially increased by the administration of dobutamine, it was decreased by the administration of the beta-blocker esmolol and preload was significantly increased with a plasma expander. A software exclusively developed by the Institute of Experimental Physics was used for data acquisition as well as data presentation and analysis (Fig. 3). During the examination we began to realize that we were generating loop diagrams and could calculate elastance.

\section{Feasibility study - Method}

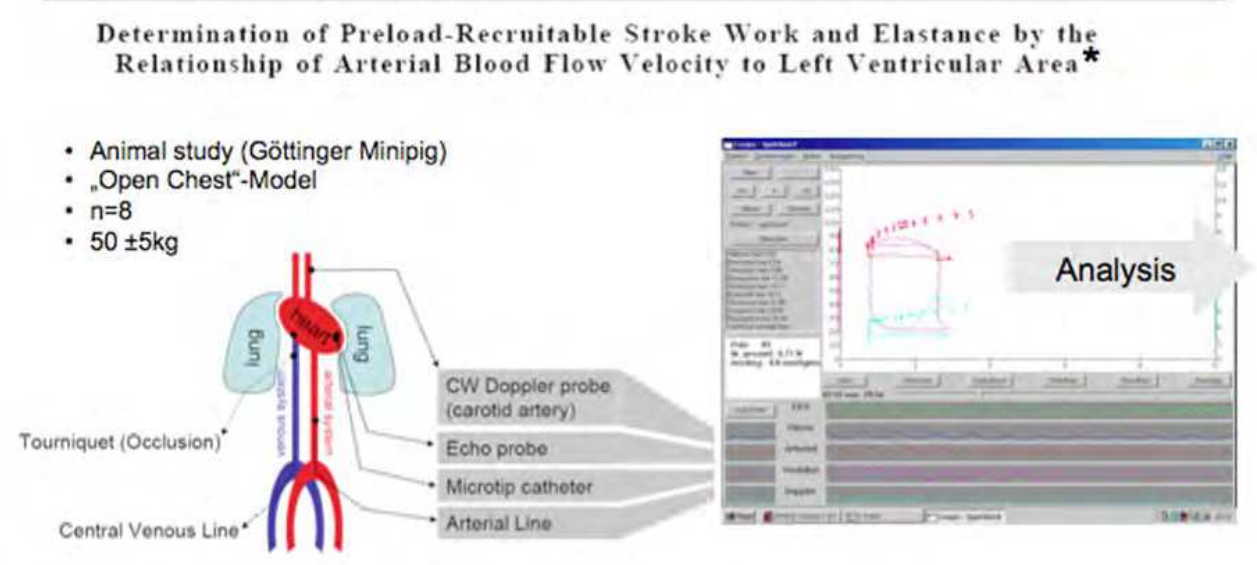

Sequential intervention with

1. Dobutamin $(5 \mu \mathrm{g} / \mathrm{kgKG}$, Inotrpy $\uparrow)$

2. Esmolol $(0,5 \mathrm{mg} / \mathrm{kgKG}$, Inotropy $\downarrow)$

3. Plasmaexpander (10 $\mathrm{ml} / \mathrm{kgKG}$, Preload $\uparrow)$

"Broscheit J. Kessler M, ot al. J Cardiothorac Vasc Anesth. 2004 Aug: 18(4): 415-22

Fig. 3. Diagram for the experiment set-up of the study "Determination of Preload Recruitable Stroke Work and Elastance by the Relation of Arterial Blood Flow Velocity to Left Ventricular Area".

The data in table $2(3 b)$ show that the change in contractility was reliably detected through the change of slope of the individual elastance curves. A change of preload through the plasma expander did not influence the slope of the elastance curves.

To sum up, this study showed that contractility can be estimated with parameters which are deduced from flow-area relationships. 

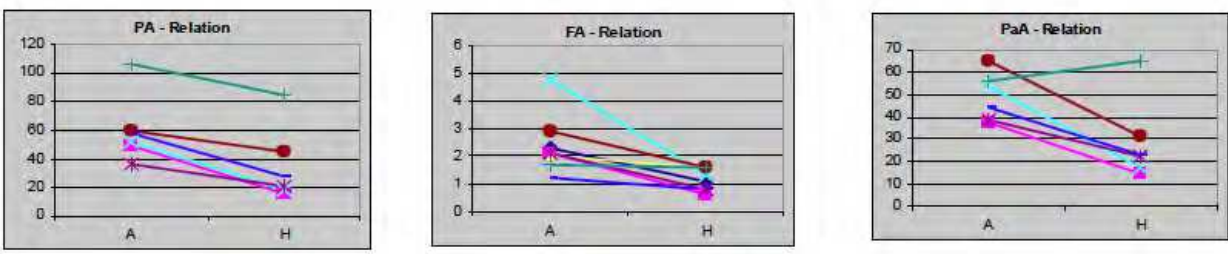

Abbreviations: PA - LVpressure vs. LVarea relation [mmHg/cm²]

FA - blood flow velocity vs. LVarea relation $\left[\mathrm{cm} / \mathrm{s} / \mathrm{cm}^{2}\right]$

$\mathrm{PaA}$ - art. rad vs. LVarea relation $\left[\mathrm{mmHg} / \mathrm{cm}^{2}\right]$

\begin{tabular}{ccccccccc}
\hline \multicolumn{4}{c}{ PA - Relation } & \multicolumn{3}{c}{ FA - Relation } & \multicolumn{3}{c}{ PaA- Relation } \\
\hline B & E & $\Delta$ & B & E & $\Delta$ & B & E & $\Delta$ \\
Mean 60.0 & 34.5 & $45.4^{*}$ & 2.4 & 1.2 & $45.3^{*}$ & 49.2 & 29.9 & $42.6 *$ \\
\pm SD $\pm 24.0 \pm 22.7 \pm 20.0$ & \pm 1.1 & $\pm 10.8 \pm 24.2 \pm 15.9$ & \pm 0.4 & \pm 30.2 \\
\hline
\end{tabular}

$\mathrm{B}=$ baseline, $\mathrm{E}=$ Esmolol $0.5 \mathrm{mg} / \mathrm{kgBW}$,

$\Delta=$ increase of the slope in $\%, *=$ signtest $p<0,05$

\section{$\rightarrow$ Inotropic changes can be detected by the flow-area relation}

Fig. 3b. Feasibility study - Results

\section{Time-varying elastance concept applied to the relation of carotid arterial flow velocity and left ventricular area}

In the previous study, changes in inotropy could in fact be detected with the help of the flow-area relationship and the following study was to answer the question as to how this procedure corresponds to the standard procedure.

In an animal experiment, 25 Göttinger minipigs were studied in a closed chest preparation. After a puncture of the femoral artery, the conductance catheter was placed in the left ventricle under fluoroscopy. The cross-sectional LV area was determined in this study using a transthoracic probe and the arteria carotis communis was studied as before. A pulmonalis catheter was used for the calibration of the conductance catheter and a Forgarty catheter, which was advanced into the inferior vena cava, was used for preload reduction. The central venous catheter served as a line for the pharmacological interventions. Like in the previous study, contractility was sequentially increased by the administration of dobutamine, it was decreased by the administration of the beta-blocker esmolol and preload was significantly increased with a plasma expander. Additionally, afterload reduction was induced through akrinor.

For the collection and processing of data, software developed by Paul Steendijk from the experimental cardiology of the University Leiden was used in this study. Pressure volumes 
and flow-area relationships could be described using this software. The elastance of the LV pressure-volume relationship is referred to as $\mathrm{E}_{\mathrm{es}}$ in literature and we called the elastance of the flow-area relationship $E^{\prime}$ es.

- Animal study (Göttinger Minipig)

- „Closed Chest“"-Modell

- $n=25$

- $50 \pm 5 \mathrm{~kg}$

Pressure-volume relationship
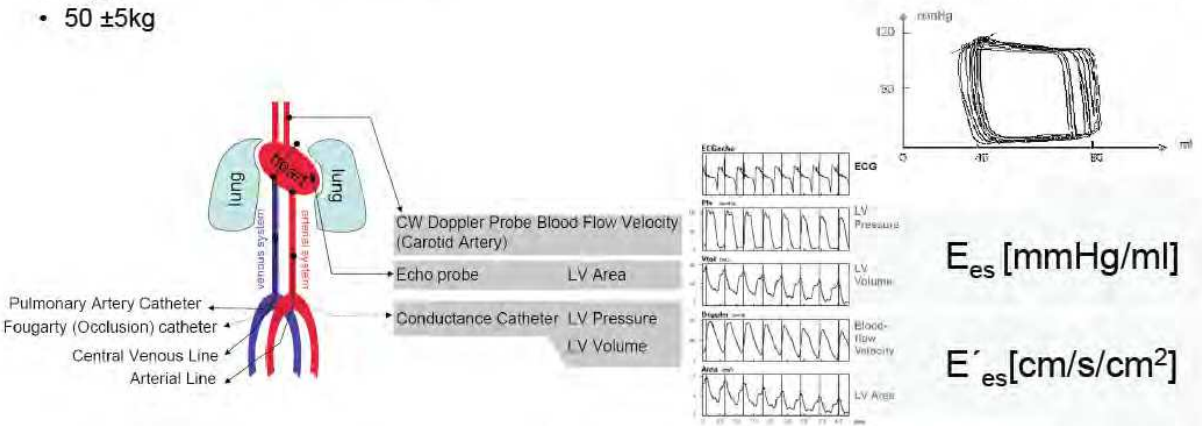

\section{$\mathrm{E}_{\mathrm{es}}[\mathrm{mmHg} / \mathrm{ml}]$}

$E_{\text {es }}^{\prime}\left[\mathrm{cm} / \mathrm{s} / \mathrm{cm}^{2}\right]$

Fig. 4. Diagram for the experiment set-up of the study "Time-Varying Elastance Concept Applied to the Relation of Carotid Arterial Flow Velocity and Left Ventricular Area"

\begin{tabular}{|c|c|c|c|c|c|}
\hline$n-25$ & Baseline & Dobutamine & Esmolot & Akrinor & Volume \\
\hline HR (bpm) & $64 \pm 11$ & $94 \pm 32^{\circ}$ & $56 \pm 7$ & $64 \pm 23$ & $60 \pm 19$ \\
\hline$E_{00}(\mathrm{mmHg} / \mathrm{mL})$ & $5.8 \pm 3.04$ & $10.1 \pm 4.19^{\circ}$ & $3.7 \pm 2.4^{*}$ & $8.31 \pm 3.58$ & $6.1 \pm 2.8$ \\
\hline $\mathrm{E}_{\infty}^{\prime}\left(\mathrm{cm}^{3} / \mathrm{min}\right)$ & $0.68 \pm 0.288$ & $1.24 \pm 0.458^{*}$ & $0.44 \pm 0.15^{\circ}$ & $0.98 \pm 0.379$ & $0.69 \pm 0.283$ \\
\hline
\end{tabular}

NOTE All interventions were performed after complete reversal of hemodynamic changes to baseline. HR, heart rate; Ees, time-varying elastance; $E^{\prime} e s$, time-varying elastance of velocity; $L V$, area relation; ${ }^{*} p<0.05$ versus baseline.

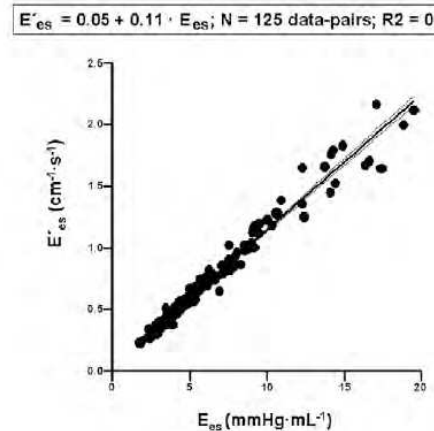

Mean $=0.017 \mathrm{SD}=0.078$

$\rightarrow$ acceptable agreement of both methods

Broscheit J, Steendijk P, et al. J Cardiothorac Vasc Anesth. 2006 Jun;20(3):340-6.

Fig. 4b. Validational study (Conductance-Catheter) - Results

In relation to the initial values, the values obtained from both procedures displayed changes in inotropy. A regression analysis was carried out using the pooled data. A significant linear 
correlation between the two measuring methods became evident. The Blant-Altman analysis showed that both methods correspond to each other acceptably.

\section{The relationship between carotid blood-flow velocity and left ventricular area during acute regional ischemia}

This study was to answer the question as to how the two measuring methods would correspond to each other in the case of a myocardial wall motion abnormality.

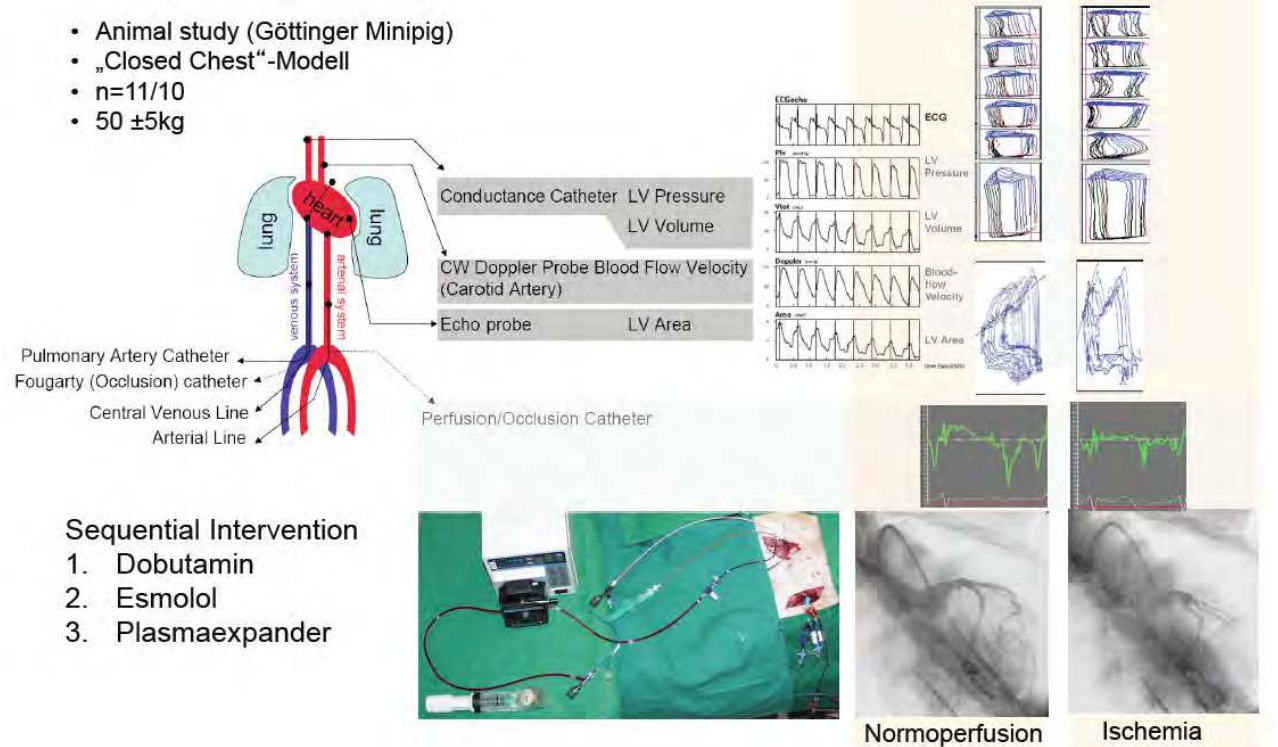

Fig. 5. Diagram for the experimental set-up of the study "The Relationship between Carotid Blood-flow Velocity and Left Ventricular Area during Acute Regional Ischemia".

In an animal experiment, 11 Göttinger minipigs were studied in a closed chest preparation. We advanced a coronary occlusion-perfusion catheter into the ramus circumflexus of the left coronary artery from the arteria femoralis. This catheter makes it possible to occlude a coronary artery while at the same time perfusing it with arterial blood using an adjustable roller pump. Standardized reduction of myocardial wall motion in the circulation area of the coronary artery was monitored by determining the systolic, radial strain rate. The strain rate is the rate of myocardial deformation and thus a unit of measurement for myocardial function. As the arteria femoralis was being used by the catheter, we advanced the conductance catheter through the right arteria carotis communis. Apart from that, preparation was the same as in the previous study.

Fig. 4 shows the loop diagram under normal perfusion and under ischemic conditions. The segmental loops of the conductance catheter deform under ischemia in the corresponding areas. This deformation was used for the calculation of an internal flow fraction, which arises when myocardial contraction cannot be completely transformed into an arterial flow. 


\begin{tabular}{|c|c|c|c|c|c|}
\hline & Baseline & Dobutamine & Esmolal & Ringer's Lactate & Perfusion State \\
\hline $\mathrm{E}_{e s}(\mathrm{mmH} / \mathrm{mL})$ & $6.9 \pm 2.7$ & $12.8 \pm 5.4^{*}$ & $4.4 \pm 1 . t^{2}$ & $6.4 \pm 2.3$ & Normal \\
\hline$E_{s}(m m H g / m L)$ & $7.7 \pm 4.2$ & $11.8 \pm 5.9^{*}$ & $4.9 \pm 2.6$ & $5.0 \pm 1.5$ & Ischemic \\
\hline $\mathrm{E}_{\mathrm{os}}^{\prime}\left(\mathrm{mL} / \mathrm{s}^{\prime} \mathrm{cm}^{2}\right)$ & $0.54 \pm 0.18$ & $1.15 \pm 0.42^{\circ}$ & $0,38 \pm 0.14^{*}$ & $0.56 \pm 0.13$ & Normal \\
\hline $\begin{array}{l}F^{\prime} \quad i m \mid / s / m^{21} \\
\operatorname{FFF}_{\mathrm{sps}}(\%)\end{array}$ & $\begin{array}{r}n 59+013 \\
10 \pm 17.7\end{array}$ & $\begin{array}{l}n 28+n 23 * \\
12 \pm 14\end{array}$ & $\begin{array}{c}027+n 11^{\circ} \\
11 \pm 8.9\end{array}$ & $\begin{array}{c}\mathrm{A1}+011 *+ \\
21 \pm 12.9\end{array}$ & $\begin{array}{l}\text { lenthernis } \\
\text { Normal }\end{array}$ \\
\hline $\mid \mathrm{FF}_{p p p}(\%)$ & $37 \pm 24.7 t$ & $27 \pm 24.5$ & $35 \pm 20.7 t$ & $21 \pm 12.9^{*}$ & Ischemic \\
\hline
\end{tabular}

NOTE. Normal perfused myocardium $n=11$; ischemic conditions, $n=10$. Abbreviations: Ees, end-systolic elastance calculated from the pressure-volume relation; $E=e s$, end-systolic elastance calculated from the flow-area relation; IFFsys, systolic internal flow fraction. *Significance versus corresponding baseline value $(p<0.05)$, †Significance versus corresponding nonischemic value $(p<0.05)$.
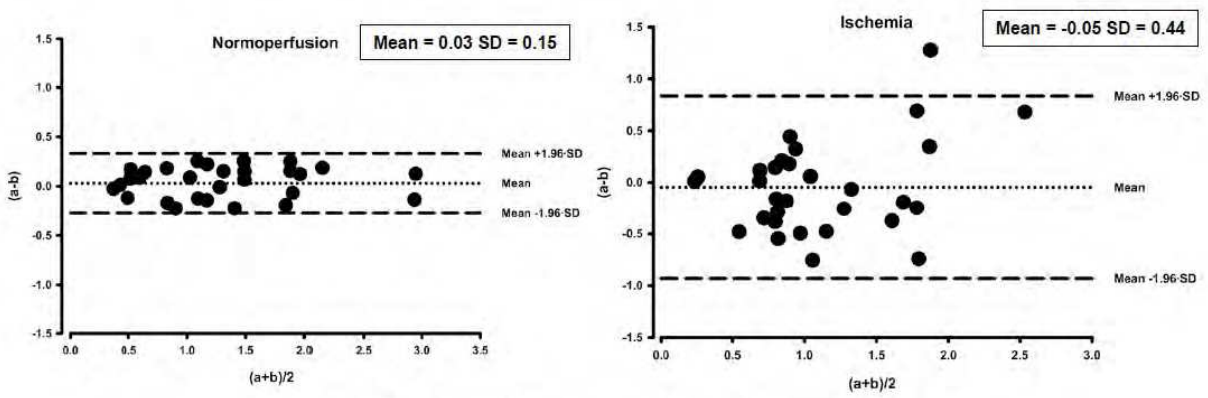

$\rightarrow$ Decreasing agreement of both methods

Broscheit J, Weidemann F, Strotmann J, et al. J Cardiothorac Vasc Anesth. 2008 Dec;22(6):823-31

Fig. 5b. Validational study during regional ischemia - Results

As the graph is directly taken from another journal, please get the copyright. I do realize that the author for this chapter is also the author for that article. However, the copyright need to be obtained as a formality from the journal. Table 1 (III 5b) shows that both procedures, independent of myocardial perfusion, could detect changes in inotropy. What stands out, however, is that the application of a plasma expander under myocardial ischemia leads to significant changes of the slope of the flow-area relationship compared to the initial values. The internal flow fraction also changed significantly under these conditions. Regression analysis in Fig. 5 (do you mean $5 b$ ? 5 is not a statistical analysis under ischemic conditions showed a decrease in the regression coefficient, linear correlation remained significant, however. The Bland-Alman analysis in Fig. 6 showed that the correspondence of the two parameters decreases.

The results of the study carried out showed that a valid assessment of myocardial contractility is possible with the flow-area relationship. Myocardial wall motion abnormalities constitute a limitation of the procedure.

\section{Dobutamine induces ineffective work in regional ischaemic myocardium: An experimental strain rate imaging study}

This study is to answer the question as to whether the results of the previous study can also be reflected by parameters of regional contractility.

In an animal experiment, 11 Göttinger minipigs were studied in a closed chest preparation. We advanced a coronary occlusion-perfusion catheter into the ramus circumflexus of the left coronary artery from the arteria femoralis. This catheter makes it possible to occlude a 
coronary artery while at the same time perfusing it with arterial blood using an adjustable roller pump. Standardized reduction of myocardial wall motion in the circulation area of the coronary artery was monitored by determining the strain rate. Apart from that, radial strain of the myocardium during systole was also determined. Strain is a unit of measurement for myocardial deformation. As the arteria femoralis was occupied by the catheter, we advanced the conductance catheter through the right arteria carotis communis.

The results show that a decrease of radial strain in the ischemic region can be documented under regional ischemia. Parallel to this, regional ischemia led to an increase in radial strain in the non ischemic myocardium. The stimulation of contractility with dobutamine intensifies the effect.

The present results confirm those of the previous study, i.e. that regional ischemia of the myocardium of $30 \%$ does not lead to a decrease of global contractility because contractility of the myocardium of the non-ischemic region is increased in a compensatory way. The increase of internal flow fraction is based on this effect, as has been shown in the previous study.

\section{The relationship between carotid arterial flow and the left ventricular area is valid to indicate contractility in states of cerebral autoregulation and decreased arterial pressure}

The present study is based on the question as to whether both measuring methods correspond under the condition of an arterial hypotension. Hypotension can activate mechanisms which, independent of systemic blood pressure, ensure constant blood flow in important organs such as the heart. To determine the flow-area relationship, we measure flow velocity in large vessels which supply the brain with blood; for this reason these mechanisms could have an effect on the flow-area relationship.

In an animal experiment, we studied 9 merino sheep and measured cortical microperfusion (flux) with the laser Doppler and we also determined tissue oxygen partial pressure $\left(\mathrm{p}_{(\mathrm{ti})} \mathrm{O}_{2}\right)$ and tissue metabolism through microdialysis. We proceeded as in a validation study, the difference being that we fixed the TEE probe onto the myocardium with a minithoracotomy.

Arterial blood pressure was, on the one hand, decreased by esmolol and on the other hand by the pure vasodilator sodium nitroprusside. Both pharmaceuticals were dosed in such a way that a mean arterial pressure of $50 \mathrm{mmHg}$ could be maintained for 20 minutes.

The table shows that the hypotension triggered by sodium nitroprusside did not lead to any other changes of the circulatory system and of the cortical and myocardial parameters. The hypotension triggered by esmolol, however, led to a decrease in cardiac output and to an increase in LV end-diastolic pressure. This was associated with a decrease in cortical microcirculation as well as with a decrease in tissue oxygen partial pressure. During the decrease in tissue oxygen partial pressure, the metabolites of the anaerobic metabolism increased. Furthermore an increase in internal flow fraction ( $\left.\operatorname{IFF}_{\text {sys }}\right)$ could be observed, indicating myocardial wall motion abnormalities. The hypotension triggered by esmolol led to a critical decrease of oxygen being supplied to the cortex and to the myocardium.

As in the previous studies, a linear correlation between flow-area relationship and LV pressure could be detected under the influence of sodium nitroprusside. The correlation 
between the two relationships was acceptable as the Bland-Altman analysis shows. The decrease of contractility induced by esmolol was also detected through the flow-area relationship. But the degree of correlation and the degree of correspondence of both parameters decreased significantly. This decrease probably results from an increase of the internal flow fraction as an indication of myocardial wall motion abnormalities. This correlation could already be detected in the previous studies. It remains unclear, however, which hemodynamic constellation led to the wall motion abnormalities - the increase in end-diastolic volume and/ or the decrease of cardiac output. Both parameters determine myocardial perfusion.

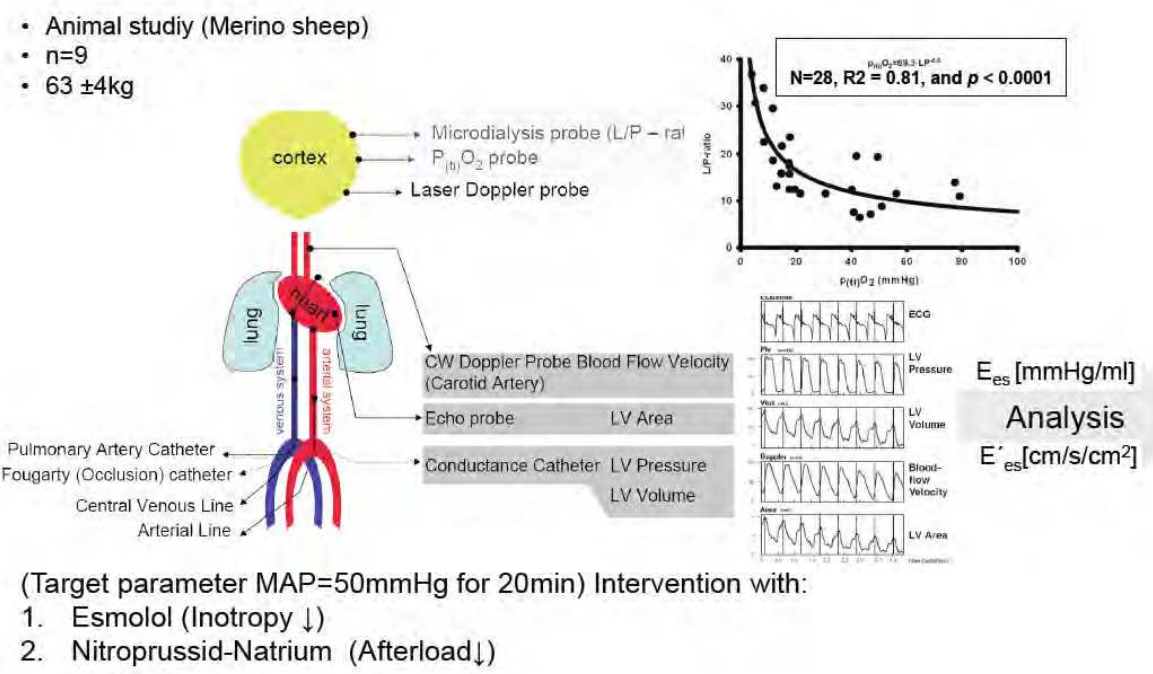

Meixensberger J, Kunze E, et al. Neurol Res. 2001 Dec;23(8):801-6

Fig. 6. Diagram for the experiment set-up of the study "The Relationship between Carotid Arterial Flow and the Left Ventricular Area is valid to indicate contractility in states of cerebral autoregulation and decreased arterial pressure

An increase in end-diastolic volume is connected with an increase in left ventricular radius. According to the law of Laplace, the increase in radius is tantamount to an increase in myocardial wall tension in diastole. During diastole the myocardium is perfused an increase in wall tension can lead to a decrease of coronary blood flow which means that oxygen supply is higher than oxygen demand. In this context, myocardial wall motion abnormalities can occur as an indication of hypoperfusion. A decrease in cardiac output is directly connected to a decrease of oxygen supply to all organs, i.e. also to the myocardium, which can result in insufficient oxygen supply.

The results of the study carried out showed that a valid assessment of myocardial contractility is possible with the flow-area relationship. 


\begin{tabular}{|c|c|c|c|}
\hline & Baseline & SNP & Esmotol \\
\hline MAP $\left[\mathrm{mmHg}^{-}\right]$ & $90 \pm 16$ & $50 \pm 11$ & $48+6^{\prime}$ \\
\hline$E_{t}\left[\mathrm{mmHg} \mathrm{cm}^{-1}\right]$ & $30 \pm 0.9$ & $30 \pm 07$ & $1.0 \pm 0.2^{n}$ \\
\hline$E_{n i}^{*}\left[\mathrm{~cm}^{-3}\right]$ & $D .89 \pm 024$ & $0.75+0.27$ & $036+021 \%$ \\
\hline Flux $\left[m m-s^{-1}\right]$ & 1 & $0.84 \pm 0.20$ & $0.63 \pm 0.30^{*}$ \\
\hline $\mathrm{P}_{m} \mathrm{O}=[\mathrm{mmH} \mathrm{g}]$ & $33 \pm 23$ & $34 \pm 7$ & $14 \pm 13^{2+}$ \\
\hline LP-ratio $\mathrm{H}$ & $12 \pm 3$ & $19 \pm 8$ & $28 \pm 15^{* *}$ \\
\hline
\end{tabular}

Abbreviations: Ees, endsystolic elastance; E'es end-systolic elastance of the flow velocity-area relationship; Flux - cortical microcirculation; L/P-ratio, ratio of cortical lactate and pyruvate values; MAP, mean arterial pressure; p(ti)O2. cortical partial oxygen pressure in the tissue; SNP, sodium nitroprusside. \# $p<$ 0.05 compared with baseline. $+p<0.05$ compared with SNP.

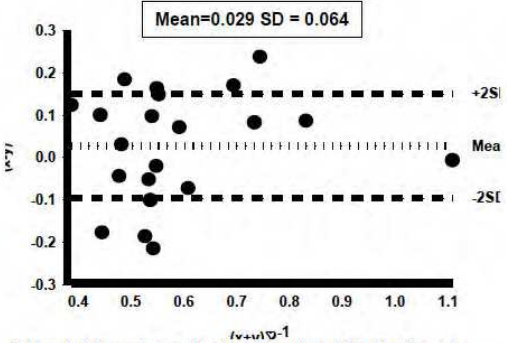

Bland-Altman analysis showing the limits of agreement and bias comparing conductance catheter derived Ees and ultrasonic based E'es. The limits of agreement (1.96 SD) were 0.13

$\rightarrow$ acceptable agreement of both methods

Broscheit J, Kunze E, et al. I J Anesthesiology. 2008 Jan;18 (1):1-16

Fig. 6b. Validational study during arterial hypotension - Results

\section{Association of increased myocardial contractility and elevated end-diastolic wall tension with short-term myocardial ischemia: A pressure-volume analysis}

The present study is to answer the question whether myocardial hypoperfusion can be triggered by an LV hypervolemia, even if arterial pressure as well as cardiac output are in an "adequate" range - as literature usually calls it.

To answer this question, 15 Göttinger minipigs were studied in an open chest preparation. A catheter was placed in the arteria femoralis to measure pressure and a probe, similar to those used for transoesophageal echocardiography, was fixed on the myocardium. A microtip catheter was inserted from the apex of the left ventricle for continuous pressure measurement. A catheter for microdialysis was implanted into the myocardium in the flow area of the left coronary artery. Finally, the arteria carotis communis was dissected to fix a U-shaped 8-MHz CW Doppler probe on it. A catheter in the femoral vein was used for pharmacological interventions.

Myocardial contractility was increased permanently through continuous application of dobutamine. A steady state was assumed after 20 minutes. Esmolol was administered in such a way that the heart rate - in relation to frequency - was lowered by at least $25 \%$ for 20 minutes under continuous infusion of dobutamin. Subsequently esmolol application was stopped so that dobutamin could again unfold its contractility-increasing effect. For comparison, only Esmolol was subsequently administered to another group - to the same amount as dobutamine and esmolol had been administered in the dobutamin-esmolol 
group. As expected, the table shows that when dobutamine and esmolol are administered at the same time, the heart rate decreases and contractility decreases later as well. Through the decrease in heart rate, LV volume increases in this phase and thus - according to the law of Laplace - diastolic myocardial wall tension increases as well. Dobutamine initially stimulates contractility but despite sufficient arterial pressure and cardiac output, oxygen supply is still lower than oxygen demand. Oxygen demand is then lowered by the decrease in contractility and the indications of hypoperfusion recede under identical wall tension. When the effect of esmolol starts to wear off, the contractility-stimulating effect of dobutamin comes back first and later the heart rate increases again. During this phase, increased wall tension leads to myocardial hypoperfusion again. Esmolol alone induces increased wall tension but no myocardial hypoperfusion.

The results of the present study show that an increase in myocardial wall tension alone is not necessarily associated with myocardial hypoperfusion. If, however, oxygen demand increases in this situation, or, as in the previous study, cardiac output and arterial pressure are reduced, the oxygen supply to the myocardium can sink below its oxygen demand. In this context, myocardial wall motion disorders can form as an indication of such an imbalance which in turn can lower the correlation of the two relations.

\section{Conclusion and outlook}

The results of the examination carried out allow the conclusion that a valid estimation of myocardial contractility is possible. Myocardial wall motion abnormalities limit the measuring accuracy of this new procedure. These myocardial wall motion abnormalities can occur if increased LV end-diastolic volume is associated with low cardiac output or an increased myocardial oxygen requirement.

In further investigations we would like to try to answer the question as to whether the acute afterload reduction necessary for the determination of elastance can also be induced through a Valsalva maneuver.

By using a 3-dimensional transoesophageal echocardiography, we would like to answer the question if measuring accuracy can possibly be significantly improved. On the one hand, using 3-dimensional echocardiography, similar to what is possible with a conductance catheter, could make it possible to determine internal flow fraction and consequently to develop a corrective factor for measurement. On the other hand, using 3-dimensional echocardiography makes it possible to estimate intraventricular volumes much more precisely than with the cross-sectional LV area.

Finally the use of this procedure should be verified in clinical studies.

\section{References}

[1] Suga H, Sagawa K, Shoukas AA. Load independence of the instantaneous pressurevolume ratio of the canine left ventricle and effects of epinephrine and heart rate on the ratio. Circ Res 1973;32:314-22. 
[2] Gorcsan J, III, Morita S, Mandarino WA, et al. Two-dimensional echocardiographic automated border detection accurately reflects changes in left ventricular volume. J Am Soc Echocardiogr 1993;6:482-9.

[3] Deneault LG, Kancel MJ, Denault A, et al. A system for the on-line acquisition, visualization, and analysis of pressure-area loops. Comput Biomed Res 1994;27:61-7.

[4] Danielsen M, Ottesen JT. Describing the pumping heart as a pressure source. Journal of Theoretical Biology 2001;212:71-81.

[5] Ottesen JT, Danielsen M. Modeling ventricular contraction with heart rate changes. Journal of Theoretical Biology 2003;222:337-46.

[6] Paladino, J, Mulier, J, and Noordergraaf, A. Defining Ventricular Elastance. 1-11-0098.

[7] Strobeck JE, Sonnenblick EH. Myocardial and ventricular function. Part II: Intact heart. Herz 1981;6:275-87.

[8] Strobeck JE, Sonnenblick EH. Myocardial and ventricular function. Part I: Isolated muscle. Herz 1981;6:261-74.

[9] Frank O. Zur Dynamik des Herzmuskels. Z Biol 1895;32:370-447.

[10] Starling EH. The Linacre Lecture of the Law of the Heart. London: Longman, Greens and Co, Ltd, 1918.

[11] Seelen, P. J. A human circulatory analog computer. VIII Considerations leading to a preliminary analog of the left ventricle of the heart. 1961. Physics Lab, Univ. Utrecht. Ref Type: Internet Communication

[12] Beneken, J. E. W. A mathematical approach to cardio-vascular function. 1965. Univ. Utrecht. Ref Type: Thesis/Dissertation

[13] Liljestrand GLENG. The immediate effect of muscular work on the stroke and heart volume in man. Skand Arch Physiol 1938;80:265-82.

[14] Hill AV. The maximum work and mechanical efficiency of human muscles, and their most economical speed. J Physiol (London) 1922;56:19-41.

[15] Olufsen MS, Nadim A, Lipsitz LA. Dynamics of cerebral blood flow regulation explained using a lumped parameter model. Am J Physiol Regul Integr Comp Physiol 2002;282:R611-R622.

[16] Baan J, Jong TT, Kerkhof PL, et al. Continuous stroke volume and cardiac output from intra-ventricular dimensions obtained with impedance catheter. Cardiovasc Res 1981;15:328-34.

[17] Suga H, Sagawa K. Instantaneous pressure-volume relationships and their ratio in the excised, supported canine left ventricle. Circ Res 1974;35:117-26.

[18] Broscheit JA, Greim CA, Kessler M, Weidemann F, Roewer N: J Cardiothorac Vasc Anesth. 18(4): 415-22.

[19] Broscheit J, Greim CA, Weidemann F, Strotmann J, Steendijk P, Karle H, Roewer N: J Cardiothorac Vasc Anesth. 2006 Jun; 20(3): 340-346.

[20] Broscheit J, Weidemann F, Strotmann J, Steendijk P, Eberbach N, Karle H, Schuster F, Roewer N, Greim CA: J Cardiothorac Vasc Anesth Epub 2008 Jun 22.

[21] Weidemann F, Broscheit J, Eberbach N, Steendijk P, Voelker W, Greim C, Ertl G, Roewer N, Strotmann JM: Clin Sci (Lond). 2004 Feb; 106(2): 173-81.

[22] Broscheit JA, Weidemann F, Grein B, Lange M, Muellenbach R, Schuster F, Lindner C, Kunze E, Steendijk P, Roewer N, Greim CA: I Anesthesiology. 2009;18(1):1-16

[23] Broscheit JA, Rinck A, Anetseder M, Kessler M, Roewer N, Greim CA: J Cardiothorac Vasc Anesth. 2007 Feb;21(1):8-17 


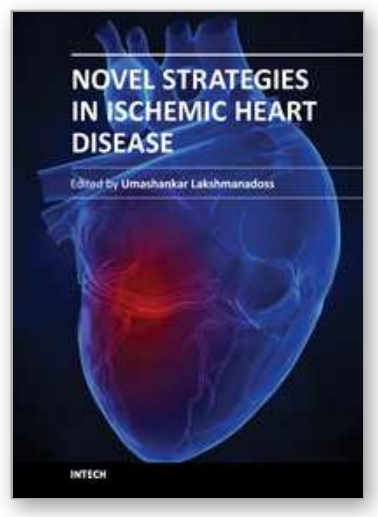

\author{
Novel Strategies in Ischemic Heart Disease \\ Edited by Dr. Umashankar Lakshmanadoss
}

ISBN 978-953-51-0184-0

Hard cover, 450 pages

Publisher InTech

Published online 29, February, 2012

Published in print edition February, 2012

The first edition of this book will provide a comprehensive overview of ischemic heart disease, including epidemiology, risk factors, pathogenesis, clinical presentation, diagnostic tests, differential diagnosis, treatment, complications and prognosis. Also discussed are current treatment options, protocols and diagnostic procedures, as well as the latest advances in the field. The book will serve as a cutting-edge point of reference for the basic or clinical researcher, and any clinician involved in the diagnosis and management of ischemic heart disease. This book is essentially designed to fill the vital gap existing between these practices, to provide a textbook that is substantial and readable, compact and reasonably comprehensive, and to provide an excellent blend of "basics to bedside and beyond" in the field of ischemic heart disease. The book also covers the future novel treatment strategies, focusing on the basic scientific and clinical aspects of the diagnosis and management of ischemic heart disease.

\title{
How to reference
}

In order to correctly reference this scholarly work, feel free to copy and paste the following:

Jens Broscheit (2012). Measurement of Myocardial Contractility in the Ischemic Heart - A Disease Immanent Uncertainty, Novel Strategies in Ischemic Heart Disease, Dr. Umashankar Lakshmanadoss (Ed.), ISBN: 978953-51-0184-0, InTech, Available from: http://www.intechopen.com/books/novel-strategies-in-ischemic-heartdisease/measurement-of-myocardial-contractility-in-the-ischemic-heart-a-disease-immanent-uncertainty

\section{INTECH}

open science | open minds

\section{InTech Europe}

University Campus STeP Ri

Slavka Krautzeka 83/A

51000 Rijeka, Croatia

Phone: +385 (51) 770447

Fax: +385 (51) 686166

www.intechopen.com

\section{InTech China}

Unit 405, Office Block, Hotel Equatorial Shanghai

No.65, Yan An Road (West), Shanghai, 200040, China

中国上海市延安西路65号上海国际贵都大饭店办公楼 405 单元

Phone: +86-21-62489820

Fax: $+86-21-62489821$ 
(C) 2012 The Author(s). Licensee IntechOpen. This is an open access article distributed under the terms of the Creative Commons Attribution 3.0 License, which permits unrestricted use, distribution, and reproduction in any medium, provided the original work is properly cited. 